\title{
Early biochemical responses of the small intestine of coeliac patients to wheat gluten
}

\author{
D S BAILEY, A R FREEDMAN, S C PRICE, D CHESCOE, \\ AND P J CICLITIRA \\ From the Division of Medicine, The Rayne Institute, United Medical \& Dental Schools of Guy's and St Thomas' \\ Hospitals, London, the Toxicology Department, The Robens Institute, University of Surrey, the Department of \\ Microstructural Studies, University of Surrey, Guildford, Surrey, and the Department of Surgery, St George's \\ Hospital Medical School, London
}

SUMmary The pathogenesis of coeliac disease has been investigated by studying the response of small intestinal hydrolases in patients with coeliac disease subject to gluten challenge. Small intestinal biopsies taken before and two and a half hours after a gluten challenge in five patients with coeliac disease who had been maintained on a gluten free diet were examined by a combination of electron and light microscopy, organ culture, pulse chase biosynthetic labelling, SDS-PAGE and autoradiography. Before the challenge, the small intestinal biopsies showed nearly normal morphology. Two and a half hours after the challenge there was deterioration in villus architecture, distortion of microvillus structure, disorganisation of the intermicrovillus pit region, an increase in lysosome like bodies in the apical cytoplasm of the luminal enterocytes and pronounced hypertrophy of the rough endoplasmic reticulum of these cells. SDS-PAGE of small intestinal biopsies from four treated coeliac patients before gluten challenge revealed normal microvillus membrane and hydrolase composition. There was a generalised reduction but no specific alteration in the pattern of polypeptide synthesis in the mucosa of the small intestine in these subjects two and a half hours after the gluten challenge. These results suggest that the generalised reduction in small intestinal brush border enzymes in coeliac patients is not the primary pathogenetic mechanism and represents a secondary effect.

Three possible mechanisms have been proposed for the pathogenesis of coeliac disease. These include lack of a specific small intestinal enzyme, ${ }^{1}$ toxic lectinlike binding of gluten to small intestinal enterocytes ${ }^{2}$ and immunological hypersensitivity to specific cereal protein epitopes. ${ }^{3}$ The primary aims of this study were to investigate whether coeliac disease is caused by either a missing small intestinal enzyme or a gluten induced loss of a specific small intestinal hydrolase. This was undertaken by examining the early morphological and biochemical responses of the small intestine of coeliac patients in remission and subject to gluten challenge by a combination of electron and light microscopy, organ culture, pulse chase biosynthetic labelling, sodium dodecyl sulphate poly-

Address for correspondence: Dr P J Ciclitira, The Rayne Institute, St Thomas' Hospital, London SE1 7EH

Received for publication 29 June 1988. acrylamide slab gel electrophoresis (SDS-PAGE), and autoradiography. A combination of these techniques permits investigation of the earliest previously noted damage to the villus morphology of the small intestine of treated coeliac patients subject to gluten challenge. Light and electron microscopy were used to study the early morphometric and ultrastructural changes of the small intestinal mucosa in these patients, whilst SDS-PAGE and biosynthetic labelling were used to look for specific abnormalities in the hydrolases of the small intestinal brush border membrane of treated coeliac patients subject to a gluten challenge. Comparison of the small intestinal mucosa of treated coeliac patients before and two and a half hours after a gluten challenge was undertaken as this was the earliest reported time at which gluten induced morphological damage had previously been noted. ${ }^{4}$ 


\section{Methods}

\section{PATIENTS}

Five patients, three women and two men, aged 25 to 57 years with coeliac disease, treated with a gluten free diet for between two and 30 years were investigated. In each case, the diagnosis had previously been established by standard criteria. ${ }^{5}$ Informed consent was obtained from the patients before the study which was approved by the Ethical Committee of St Thomas' Hospital.

\section{EXPERIMENTAL DESIGN}

In all five subjects, a Quinton peroral hydraulic multiple biopsy instrument was positioned under fluoroscopic control in the proximal jejunum. Seven jejunal biopsies were taken at time zero and two and a half hours after the subjects had ingested $10 \mathrm{~g}$ wheat gluten suspended in $150 \mathrm{ml}$ tap water. In one of the five volunteers, additional biopsies were taken at four and six hours after the challenge.

In all five subjects one biopsy before and another two and a half hours after the gluten challenge were fixed in formal saline. These biopsies were processed in wax to $5 \mu \mathrm{m}$ sections, stained with haematoxylin and eosin and examined morphometrically under a light microscope. One of the biopsies taken from each patient before and two and a half hours after the gluten challenge was fixed in $4 \%$ glutaraldehyde, buffered with $0.1 \mathrm{M}$ sodium cacodylate $\mathrm{pH} 7.4$ and processed for electron microscopy according to criteria described by Mann et al. ${ }^{6}$ Formalin fixed sections were used to measure villus height to crypt depth ratio, epithelial surface cell height and intraepithelial lymphocyte count per 100 enterocytes.? The results are expressed as the mean \pm 1 standard deviation of 10 observations and compared statistically by a paired Student's $t$ test.

In four of the subjects five of the jejunal biopsies taken before and two and a half hours after the gluten challenge were used to compare brush border composition and membrane synthesis using a combination of organ culture, pulse chase biosynthetic labelling, SDS-PAGE, and autoradiography. These five biopsies from each patient at both time zero and two and a half hours after the challenge were cultured separately and pulse chase labelled with ${ }^{35} \mathrm{~S}$ methionine by incubating them on the grids of organ culture dishes, as described by Browning and Trier ${ }^{8}$ with $20 \mu \mathrm{Ci}$ of ${ }^{35} \mathrm{~S}$-methionine (Amersham International, High Wycombe) in $2.5 \mu \mathrm{l}$ PBS placed on the upper mucosal surface of each biopsy for 10 minutes. Just sufficient tissue culture medium was then added to the organ culture dishes to come into contact with the stainless steel grids, and the biopsies cultured for a further 110 minutes. The tissue culture medium comprised $6 \mathrm{ml}$ Trowell's T8 medium, $2 \mathrm{ml}$ NCTC 135 medium, $0 \cdot 2 \mathrm{ml} 200 \mathrm{mM}$ L-glutamine, $0 \cdot 1$ $\mathrm{ml} 1 \mathrm{M}$ HEPES, $0.2 \mathrm{ml}$ penicillin $(5000 \mathrm{U} / \mathrm{ml})$, plus streptomycin $(5000 \mu \mathrm{g} / \mathrm{ml})$ and $1.5 \mathrm{ml}$ fetal calf serum to $10 \mathrm{ml}$, all the reagents for which were obtained from Gibco Limited, Paisley. The incubations were at $37^{\circ} \mathrm{C}$ in an atmosphere of $95 \% \mathrm{O}_{2}$ and $5 \% \mathrm{CO}_{2}$. The biopsies were then frozen separately in thawing isopentane over liquid nitrogen and stored in liquid nitrogen for up to a fortnight before analysis as described below. In one of the five subjects 10 additional biopsies were taken, five at four and five at six hours after the gluten challenge to assess semiquantitatively by SDS-PAGE the amount of microvillus membrane present at these times compared with the biopsies taken before and two and a half hours after the challenge.

\section{FRACTIONATION OF MUCOSAL BIOPSIES}

The five biopsies from each subject both before and two and a half hours after the challenge were independently pooled for each subject at the two time points before fractionation. These mucosal biopsies were fractionated at $4^{\circ} \mathrm{C}$ into cytoplasmic and membrane preparations by homogenisation in $300 \mathrm{mM}$ mannitol $50 \mathrm{mM}$ HEPES buffer using 20 strokes of a loose fitting Dounce homogeniser. Membranes were pelleted from the homogenate by high speed centrifugation at $100000 \mathrm{~g}$ for 60 minutes in a Beckman TL.100 centrifuge.

\section{MICROVILLUS MEMBRANE PREPARATION BY} CATION PRECIPITATION

Preparation of the adult coeliac microvillus membrane vesicles by $\mathrm{Mg}^{++}$precipitation was as previously described, ${ }^{4}$ based upon the procedure of Kessler et al, ${ }^{10}$ as modified by Gains and Hauser." Final purification was by sucrose density gradient centrifugation. Aminopeptidase activity was used routinely as a marker of enzyme activity for the microvillus membrane. Purified adult small intestinal microvillus membrane vesicles banded at an isopycnic sucrose density of approximately $1.2 \mathrm{~g} / \mathrm{ml}$ and showed an approximately 15 -fold rise in aminopeptidase activity.

SDS-POLYACRYLAMIDE GEL ELECTROPHORESIS Microvillus membranes were prepared from prechallenge biopsies with a combined wet weight of 60 $\mathrm{mg}$ and directly compared with those obtained from post challenge biopsies of the same combined wet weight by SDS-PAGE. One dimensional sodium dodecyl sulphate polyacrylamide electrophoresis (SDS-PAGE) was carried out using slabs of $7.5 \%$ polyacrylamide as described by Laemmli'2 under reducing conditions. Protein molecular weights were 

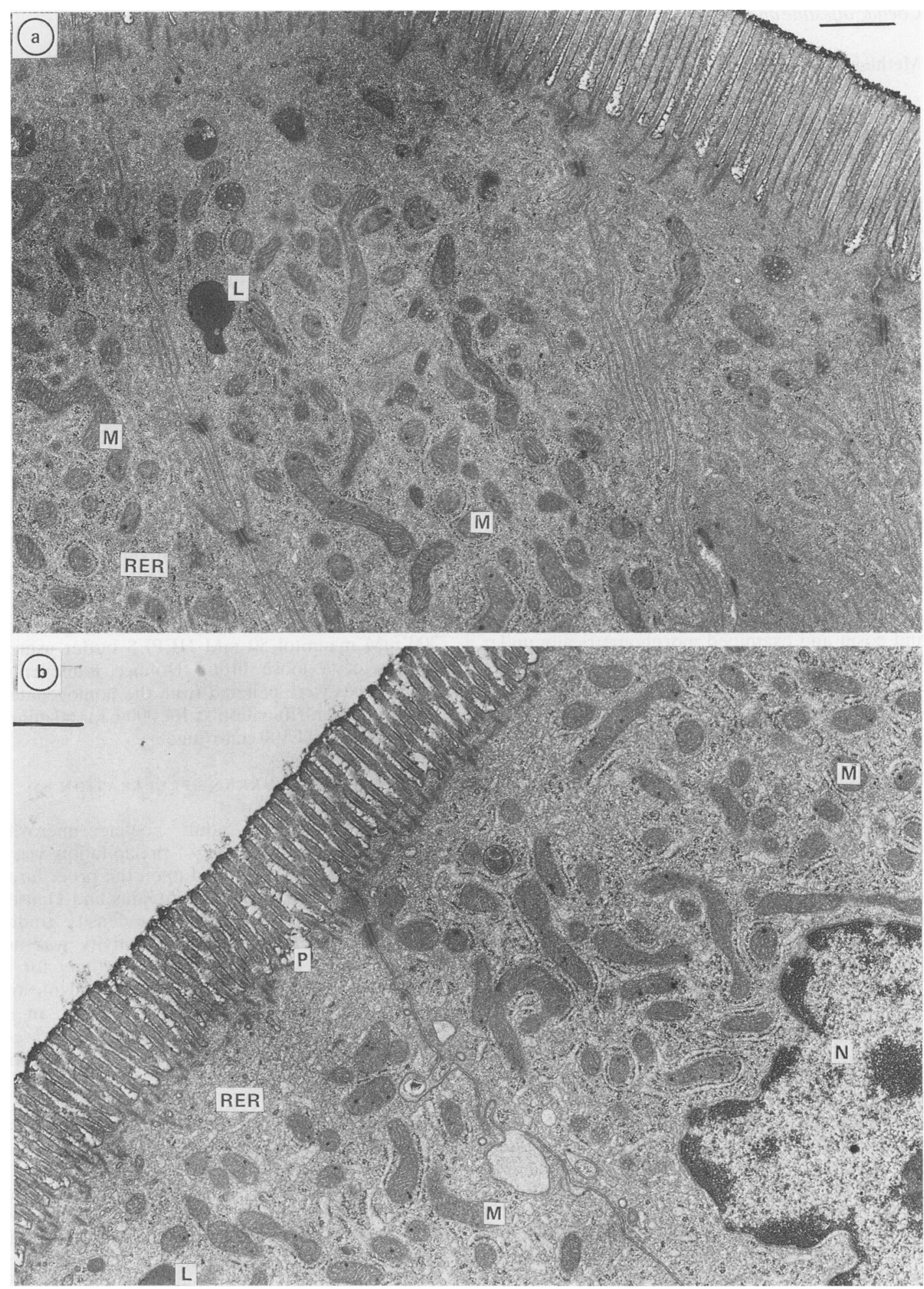

Fig. 1 Electron micrographs of enterocytes from one treated coeliac patient (a) before and (b) two and a half hours after gluten challenge. $L=L y$ sosome; $M=$ Mitochondria; $N=$ Nucleus; $P=$ Microvillus pit; $R E R=R$ Rough endoplasmic reticulum. represents $1 \mu \mathrm{m}$. 
estimated by reference to migration of standard proteins (carbonic anhydrase, $29 \mathrm{kD}$; ovalbumin 45 $\mathrm{kD}$; bovine serum albumin, $68 \mathrm{kD}$; rabbit muscle phosphorylase b, $97.4 \mathrm{kD} ; E$ Coli beta-galactosidase, $116 \mathrm{kD}$ and rabbit muscle myosin $205 \mathrm{kD}$, all obtained from Sigma Chemicals, Poole, Dorset). Proteins were detected by Coomassie blue and silver staining. ${ }^{13}{ }^{35} \mathrm{~S}$-methionine incorporation was investigated by gel autoradiography.

ENZYMATIC DETERMINATIONS

Aminopeptidase N (EC 3.4.11.2) was assayed as described by Wachsmuth et $a l,{ }^{14}$ and protein was measured by the method of Lowry et al..$^{15}$

\section{Results}

STRUCTURE AND ULTRASTRUCTURE OF COELIAC SMALL INTESTINAL MUCOSA

Before challenge, examination of the small intestinal biopsies from the five coeliac patients on a gluten free diet by light and transmission electron microscopy revealed that the jejunal mucosa of the coeliac patients possessed normal or nearly normal villus architecture with the exception of patient No 2 in whom the intraepithelial lymphocyte count was raised at $64 / 100$ enterocytes. In all five subjects the biopsies revealed a well developed brush border, with elaborate microvilli - an example of which is shown in Figure 1a. The results of the light microscope morphometry are presented in the Table.

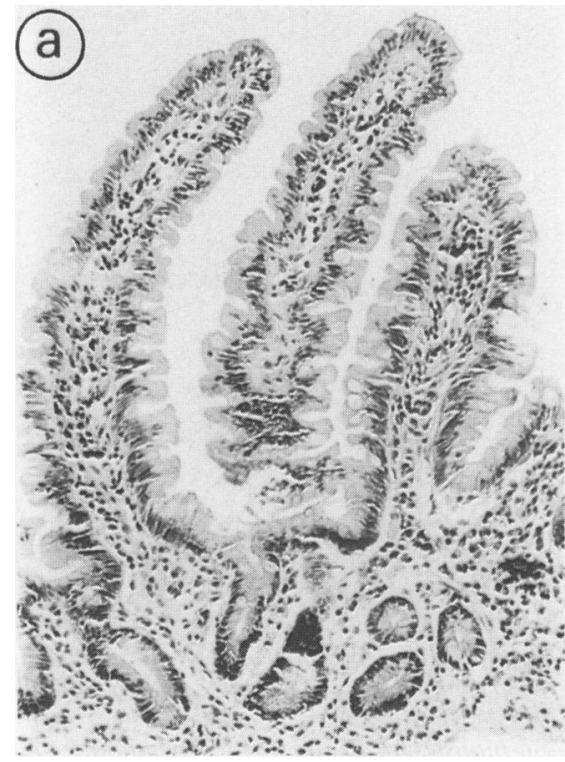

Table Morphometric variables of jejunal biopsies from five coeliac patients before $(A)$ and two and a half hours after $(B)$ a gluten challenge

\begin{tabular}{|c|c|c|c|c|c|}
\hline \multirow{2}{*}{$\begin{array}{l}\text { Patient } \\
\text { No }\end{array}$} & \multicolumn{2}{|c|}{$\begin{array}{l}\text { Villus height: } \\
\text { crypt depth }\end{array}$} & $\begin{array}{l}\text { Epithelial surface } \\
\text { cell height }(\mu \mathrm{m})\end{array}$ & \multicolumn{2}{|c|}{$\begin{array}{l}\text { Intraepithelial } \\
\text { lymphocytes/100 } \\
\text { enterocytes }\end{array}$} \\
\hline & $A$ & $B$ & $A$ & $A$ & $B$ \\
\hline 1 & $1.85(C$ & $0 \cdot 1) 1 \cdot 57(0 \cdot 1)$ & $42 \cdot 0(2 \cdot 1) 30 \cdot 3(1 \cdot 5)$ & $23 \cdot 4(3)$ & $35 \cdot 1(2 \cdot 9)$ \\
\hline 2 & $1.51(0$ & $0.2) 1.34(0.2)$ & $31 \cdot 1(1 \cdot 9) 27 \cdot 6(2 \cdot 8)$ & $64 \cdot 0(4 \cdot 7)$ & $71 \cdot 3(4 \cdot 4)$ \\
\hline 3 & $2.88(C)$ & $0.2) 2.27(0.2)$ & $35.5(1.9) 35 \cdot 1(1.2)$ & $22 \cdot 6(3 \cdot 6)$ & $31 \cdot 8(3 \cdot 2)$ \\
\hline 4 & $3 \cdot 16(c)$ & $0.2) 1.9(0.2)$ & $35.9(2.4) 35 \cdot 1(2 \cdot 2)$ & $30.7(1.9)$ & $62 \cdot 9(4 \cdot 2)$ \\
\hline 5 & $2.01(($ & $0.1) 1.37(0 \cdot 1)$ & $38.2(1.6) 25 \cdot 3(1.9)$ & $28 \cdot 2(3 \cdot 2)$ & $46 \cdot 8(3 \cdot 0)$ \\
\hline $\begin{array}{l}\text { Mean } \\
\quad(1 \mathrm{SD})\end{array}$ & $2 \cdot 3(0$ & $0.7) 1.7(0.4)$ & $36 \cdot 5(4 \cdot 0) 30 \cdot 7(4 \cdot 4)$ & $33 \cdot 8(17)$ & $49 \cdot 6(17)$ \\
\hline \multicolumn{3}{|c|}{ Significance } & NS & \multicolumn{2}{|c|}{$\mathrm{p}<0.0 .5$} \\
\hline
\end{tabular}

Two and a half hours after the gluten challenge in all five subjects there was mildly abnormal villus architecture as shown in Fig. $2 b$, with a fall in villus height:crypt depth ratio $(\mathrm{p}<0.05)$, a fall in epithelial surface cell height, which failed to reach significance and a rise in intraepithelial lymphocyte count $(p<0.05)$, the results of which are shown in the Table. Electron microscopy of the biopsies taken two and a half hours after the gluten challenge, revealed microvillus membrane perturbation, extensive intermicrovillus pit hypertrophy, hypertrophy of the rough endoplasmic reticulum and the presence of numerous lysosome like organelles in the apical part

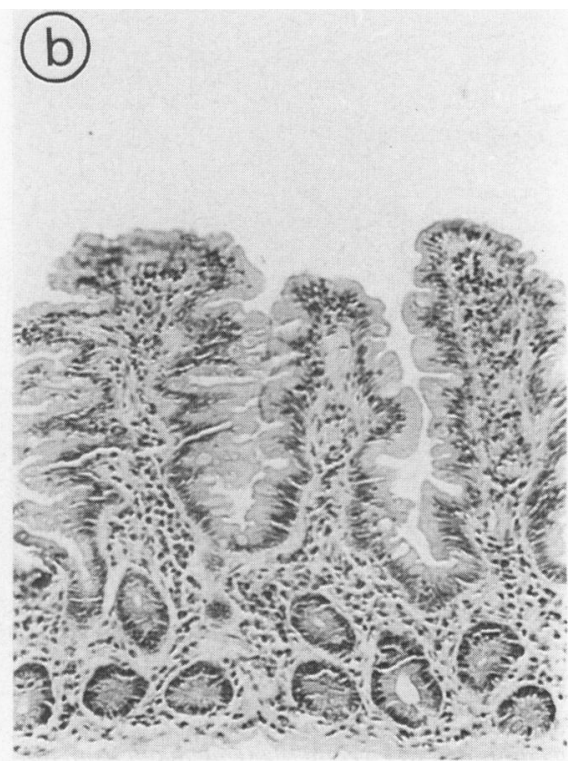

Fig. 2 Light microscopy of small intestinal mucosa from one treated coeliac patient - (a) before and $(b)$ two and a half hours after gluten challenge. 
of the surface enterocytes (Fig. 1) in all five subjects. No direct continuity between the apical membrane and the cytoplasmic lysosomes was evident in any of the sections examined.

\section{POLYPEPTIDE COMPOSITION OF THE}

PRECHALLENGE MICROVILLUS MEMBRANE

The small intestinal microvillus membrane from the four coeliac patients before gluten challenge possessed a normal complement of proteins with a dominant actin band at $47 \mathrm{kD}$ and a group of high molecular weight proteins at 127 to $164 \mathrm{kD}$. The latter correspond to the microvillus hydrolases. ${ }^{\text {it }} \mathrm{An}$

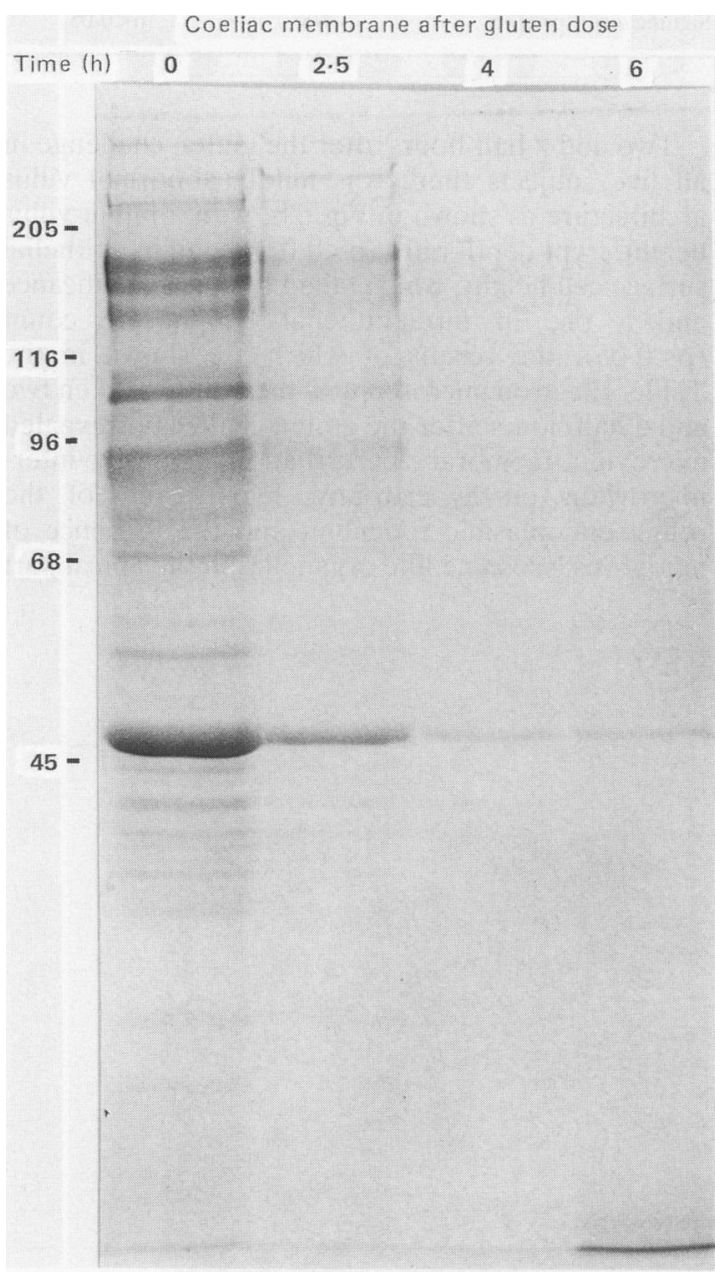

Fig. 3 Seven and a half per cent SDS-PAGE stained with Coomassie blue of microvillus membranes prepared from biopsies with a combined wet weight of $60 \mathrm{mg}$ taken from one coeliac patient before $(0 \mathrm{~h})$, two and a half, four, and six hours after gluten challenge. Molecular weights of 205, 116, 96,68 , and 45 kilodaltons are marked at the side. example of this in one of the patients, documented by one-dimensional SDS-PAGE is shown in the first track of Fig. 3. These constituents closely resemble the polypeptide components of normal jejunal microvillus membranes. ${ }^{1718}$

\section{MICROVILLUS MEMBRANE AFTER GLUTEN}

CHALLENGE

Examination of Coomassie Blue staining of SDSPAGE of microvillus membranes from a pooled quantity of $60 \mathrm{mg}$ of both pre and post challenge biopsies taken from each subject before and after the challenge revealed no change in their composition

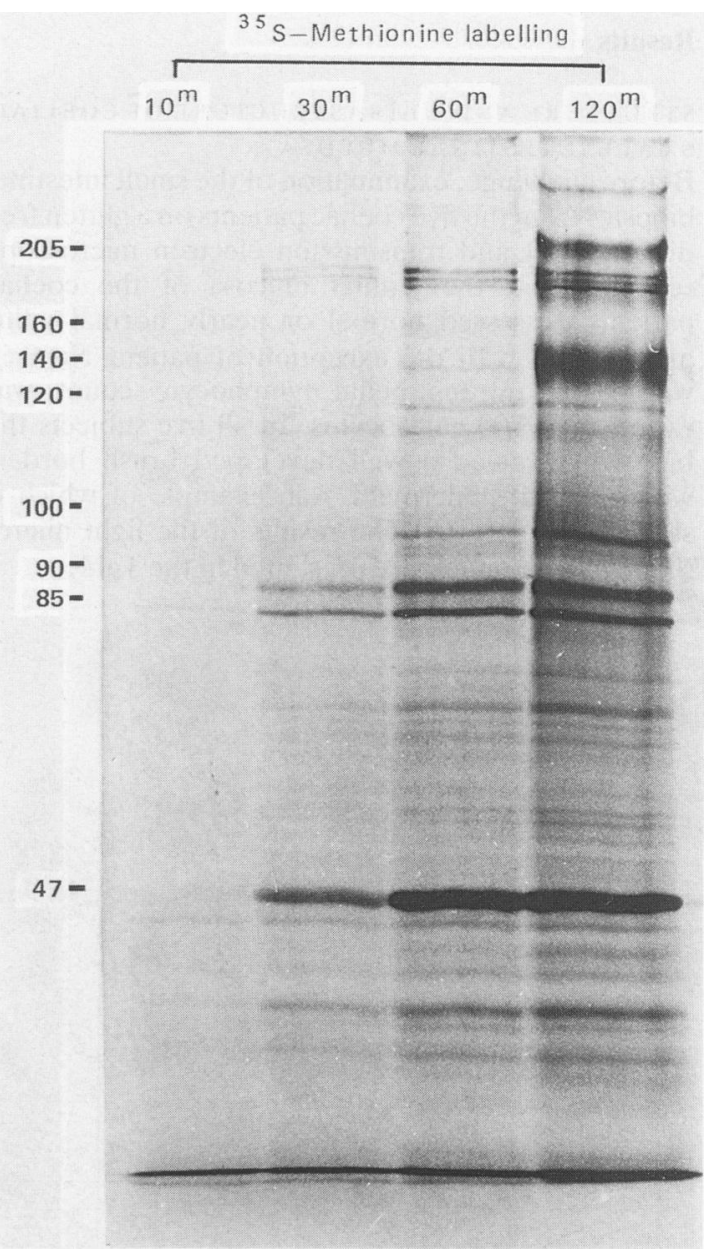

Fig. 4 Gel autoradiograph of microvillus membrane preparations from one coeliac patient who had been taking a gluten free diet before gluten challenge, after pulse labelling the biopsies for 10 min with "S-methionine followed by 10,30 , 60 , and 120 min cold chase with methionine in tissue culture medium. Molecular weights of 205, 160, 140, 120, 100, 90, 85 , and 47 kilodaltons are marked at the side. 


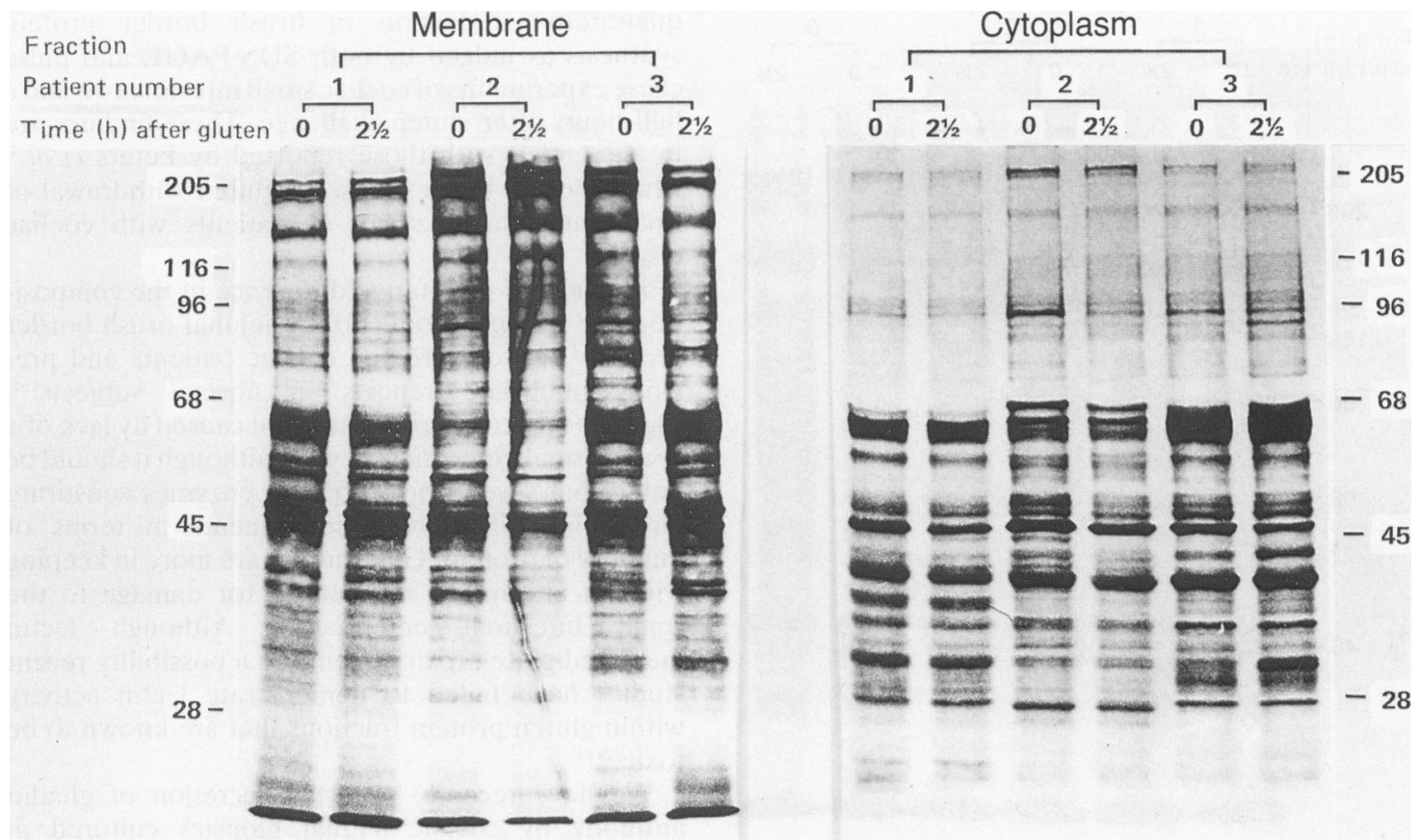

Fig. 5 Gel autoradiographs of total membrane and cytoplasmic fractions of biopsies taken before and two and a half hours after gluten challenge from three coeliac subjects who had been taking a gluten free diet. The biopsies were pulse labelled with "S-methionine and chased with cold methionine in tissue culture medium for 120 minutes. Molecular weights of 205, 116 , $96,68,45$, and 28 kilodaltons are marked at the side.

but a marked decrease in yield in the four subjects examined in this way as shown in Fig. 3 track 2 . The progressive loss of microvillus membrane at four and six hours after challenge in the single patient who had biopsies at these times is shown in Fig. 3 tracks 3 and 4. Any defect in the apical membrane therefore seems to reflect diminished microvillus membrane synthesis rather than abnormal structure.

BIOSYNTHETIC STUDIES

The results of ${ }^{35} \mathrm{~S}$-methionine pulse chase SDSPAGE autoradiography studies using mucosal biopsies pooled separately for each subject from three of the four subjects investigated in this way are shown in Figs 4-6. Purification of the microvillus membrane from biopsies taken before gluten challenge showed that synthesis of a complete spectrum of microvillus polypeptides was obtained only after a 120 minute cold chase after 10 min ${ }^{35} \mathrm{~S}$-methionine biosynthetic labelling (Fig. 4). This time period was therefore used in all the subsequent biosynthetic studies. Although clear differences in the labelled polypeptide constituents were observed between individual patients, no changes in labelled polypeptides were seen in either the total membrane or cytoplasmic fractions two and a half hours after gluten challenge (Fig. 5).

To complement these studies, microvillus membrane preparations from the same pooled biopsies for each subject before and after the gluten challenge were also examined (Fig. 6). Again, no changes in labelled microvillus polypeptides were seen subsequent to gluten challenge in any of the subjects examined. The cytoplasmic and total membrane extracts prepared from mucosal biopsies contained spectra of polypeptides which differed markedly in molecular weight (Fig. 5).

\section{Discussion}

Our results confirmed normal or near normal light and electron microscopic appearances of jejunal biopsies taken from coeliac patients in remission on a gluten free diet, in agreement with Bramble et al. ${ }^{14}$ We also found a normal complement of, and normal synthesis of microvillus membrane components in these biopsies. Two and a half hours after a $10 \mathrm{~g}$ oral gluten challenge in five treated coeliac patients we found morphological and ultrastructural damage to the jejunal mucosa confirming the findings of Bayless 


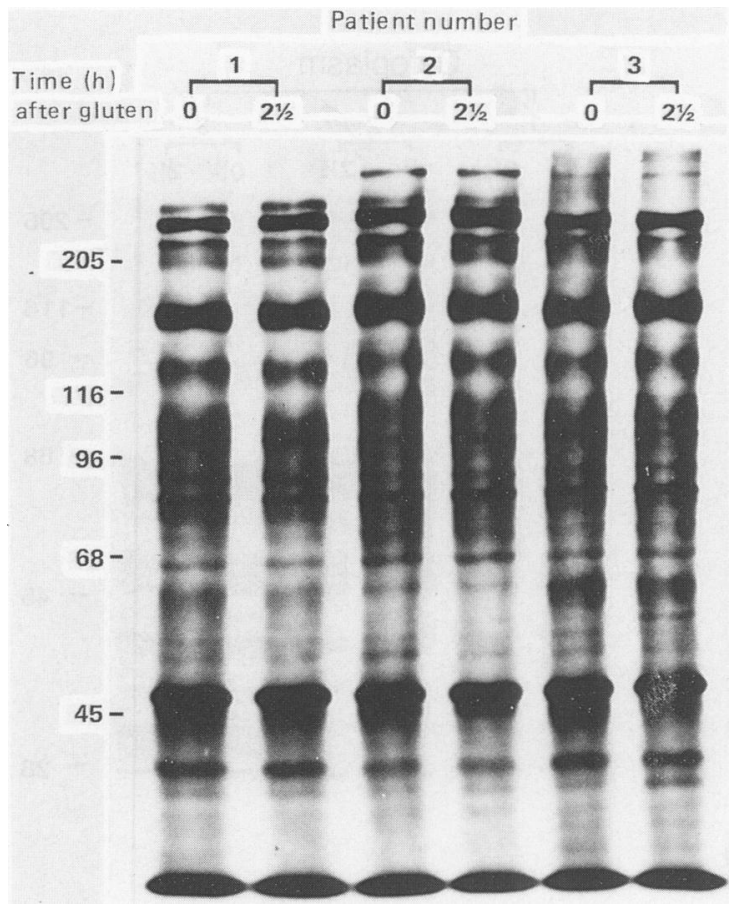

Fig. 6 Gel autoradiographs of microvillus membrane preparations from biopsies taken before and two and a half hours after gluten challenge from three coeliac subjects who had been taking a gluten free diet. The biopsies were pulse labelled with ${ }^{35} S$-methionine and chased with cold methionine in tissue culture medium for 120 minutes. Molecular weights of 205, 116, 96, 68, and 45 kilodaltons are marked at the side.

et al."21 The increased number of lysosome like particles in the apical cytoplasm of surface enterocytes has previously been reported ${ }^{21}$ and is believed to represent impending cell dissolution. It is unlikely that any of the observed changes in villus morphology were because of the presence of the biopisy capsule alone as no changes in villus morphology were noted in serial jejunal biopsies taken hourly over six hours from a treated coeliac patient challenged with $150 \mathrm{ml}$ tap water alone in a previous study. ${ }^{22}$ It is also unlikely that excessive quantities of gluten could cause non-specific toxic small bowel changes, as serial jejunal biopsy specimens obtained from normal volunteers in three previous studies showed no changes in their small intestinal villus morphology in serial jejunal biopsies after gluten challenge. ${ }^{27-25}$ Moreover it was previously established that up to $150 \mathrm{~g}$ of gluten given daily for at least eight weeks had no demonstrable histological effect on the small bowel in normal volunteers. ${ }^{26}$

Coincident with the morphological damage to the brush border microvilli we observed a generalised quantitative reduction in brush border protein synthesis as judged by both SDS-PAGE and pulse chase experiments of coeliac small intestine two and a half hours after gluten challenge. These findings are in agreement with those reported by Peters $e t a l,{ }^{27}$ who reported the response to gluten withdrawal of small intestinal enzymes in patients with coeliac disease.

The lack of qualitative difference in the composition and in vitro production of jejunal brush border proteins between treated coeliac patients and previous published reports in normal subjects ${ }^{17}$ suggests that coeliac disease is not caused by lack of a specific small intestinal enzyme, although it should be noted that several brush border enzymes constitute only minor membrane components in terms of quantity of protein. Our findings are more in keeping with an alternative mechanism for damage to the small intestinal enterocytes. Although lectin mediated gluten toxicity remains a possibility recent studies have failed to demonstrate lectin activity within gluten protein fractions that are known to be toxic. ${ }^{28} 29$

We have recently reported secretion of gliadin antibody by coeliac jejunal biopsies cultured in vitro, ${ }^{30}$ infiltration of coeliac small intestinal mucosa by $T$ lymphocytes ${ }^{22}$ and aberrant expression of HLA-class II antigens by small intestinal crypt enterocytes of treated coeliac patients within two hours of an acute gluten challenge..$^{31}$ These findings suggest a possible pathogenetic role for local cellular and antibody mediated immune mechanisms in coeliac disease. The present study has shown both morphological and biochemical damage to the enterocyte brush border membrane over a similar time course and therefore adds further weight to this hypothesis.

PJC is a Wellcome Senior Research Fellow in Clinical Science. ARF is supported by a grant from the St Thomas' Hospital Research (Endowments) Committee. We wish to thank Dr B Creamer for allowing us to study patients under his care, Mrs J Mullery for sectioning the samples for electron microscopy and Barbara E Issom for typing the manuscript. Part of this work has been published as a preliminary report in abstract form (Clin Sci 1987; 73: suppl 17: 15-6).

\section{References}

1 Van Der Kamer JH, Weijers HA. Coeliac disease: Some experiments on the cause of the harmful effect of wheat gliadin. Acta Paediatr Scand 1955; 4: 465-9.

2 Weiser MM, Douglas AP. An alternative mechanism for gluten toxicity in coeliac disease. Lancet 1976; i: 567-9. 
3 Ferguson A, MacDonald TT, McClure JP, Holden RJ. Cell-mediated immunity to gliadin within the smallintestinal mucosa in coeliac disease. Lancet 1975; i: 895-7.

4 Ciclitira PJ, Evans DJ, Fagg HLK, Lennox ES, Dowling RH. Clinical testing of gliadin fractions in coeliac patients. Clin Sci 1984; 66: 357-64.

5 Meeuwisse G. Diagnostic criteria in coeliac disease. Acta Paediatr Scand 1970; 59: 461-4.

6 Mann AH, Price SC, Mitchell FE, Grasso P, Hinton RH, Bridges JW. Comparison of the short-term effects of Di (2-ethylhexyl) phthalate, Di (n-Mexyl) phthalate, and Di (n-octyl) phthalate in rats. Toxicol Appl Pharmacol 1985; 77: 116-32.

7 Ferguson A, Murray D. Quantitation of microepithelial lymphocytes in human jejunum. Gut 1971; 12: 988-94.

8 Browning TH, Trier JS. Organ culture of mucosal biopsies of human small intestine. J Clin Invest 1969; 48: 1423-32.

9 Bailey DS, Cook A, McAllister G, Moss M, Mian N. Structural and biochemical differentiation of the mammalian small intestine during development. $J$ Cell Sci 1984; 72: 195-212.

10 Kessler M, Ocuto O, Storelli C, Murer H, Muller M, Semenza G. A modified procedure for the rapid preparation of efficiently-transporting vesicles from small intestinal brush border membranes. Biochem Biophys Acta 1978; 506: 136-54.

11 Gains N, Hauser H. Detergent-induced proteolysis of rabbit intestinal brush border vesicles. Biochim Biophys Acta 1981; 646: 211-7.

12 Laemmli UK. Cleavage of structural proteins during the assembly of the head of bacteriophage T4. Nature (London) 1970; 227: 680-5.

13 Wray W, Boulikas T, Wray VP, Hancock R. Silver staining of proteins in polyacrylamide gels. Anal Biochem 1981; 118: 197-203.

14 Wachsmuth ED, Fritze I, Pfleiderer G. An aminopeptidase occurring in pig kidney. I. An improved method of preparation. In: Physical and enzymatic properties. Biochemistry 1966; 5: 169-74.

15 Lowry OH, Rosebrough NJ, Farr AL, Randall RJ. Protein measurement with the Folin-phenol reagent. J Biol Chem 1951; 193: 265-75.

16 Zweibaum A, Hauri HP, Sterchi F, et al. Immunohistological evidence, obtained with monoclonal antibodies of small intestinal brush-border hydrolases of human colon cancer and foetal colon. Int J Cancer 1984; 34: 591-8.

17 Pemberton PW, Holmes R, Lobley RW. Analysis of human small intestinal microvillus membranes by two- dimensional electrophoresis. Biochem Soc Trans 1983; 11: $397-8$.

18 Turnbull G, Bailey D. Characterisation of brushborders from the human small intestinc. Biochem Soc Trans 1985; 14: 783-4.

19 Bramble MB, Zucoloto S, Wright NA, Record CO. Acute gluten challenge in treated adult cocliac discase: morphometrical and enzymatic study. Gut 1985; 26: 169-74.

20 Bayless TM, Rubin SE, Topping TM, Yardley JH. Hendrix TR. Morphological effects of gluten feeding on jejunal mucosa in cocliac disease. In: Booth $\mathrm{CC}$, Dowling RH, eds. Coeliac disease. Edinburgh: Churchill-Livingstone, 1970: 76-89.

21 Marsh MN. Immunocytes, enterocytes and the lamina propria: an immuno-pathological framework of cocliac disease. J R Coll Physicians London 1983; 17: 205-12.

22 Freedman AR, Macartney JC, Nelufer J, Ciclitira PJ. Timing of infiltration of $T$ lymphocytes induced by gluten into the small intestine in coeliac disease. J Clin Pathol 1987; 40: 741-5.

23 Weinstein WM. Latent celiac sprue. Gastroenterology 1974; 66: 489-93.

24 Leonard J, Haffenden G, Tucker W, et al. Gluten challenge in dermatitis herpetiformis. $N$ Engl J Med 1983; 308: 816-9.

25 Doherty M, Barry RE. Gluten-induced mucosal changes in subjects without overt small-bowel disease. Lancet 1981 ; i: 517-20.

26 Levine RA, Briggs GW, Harding RS, Nolte LB. Prolonged gluten administration in normal subjects. N Engl J Med 1966; 274: 1109-14.

27 Peters TJ, Jones PE, Wells GP. Analytical subcellular fractionation of jejunal biopsy specimens: enzyme activities, organelle pathology and response to gluten withdrawal in patients with cocliac disease. Clin Sci

28 Colyer J, Farthing MJG, Kumar PJ, Clark ML, Ohannesian AD, Waldron NM. Reappraisal of the 'lectin hypothesis' in the aetiopathogenesis of cocliac disease. Clin Sci 1986; 71: 105-10.

29 Colyer J, Kumar PJ, Waldron NM, Clark ML, Farthing MJG. Gliadin binding to rat and human enterocytes. Clin Sci 1987; 72: 593-8.

30 Ciclitira PJ, Ellis HJ, Wood GM, Howdle PD, Losowsky MS. Secretion of gliadin antibody by cocliac jejunal mucosal biopsies cultured in vitro. Clin Exp Immunol 1986; 64: 119-24.

31 Ciclitira PJ, Nelufer JM, Ellis HJ, Evans DJ. HLA-DR expression in coeliac small intestinal epithclium. Clin Exp Immunol 1986; 63: 101-4. 